\title{
Centenaria vigencia: visiones de la posteridad en un relato de Amado Nervo.
}

\section{Centennial standing: visions of posterity in a piece of prose by Amado Nervo.}

\author{
María Guadalupe Sánchez Robles \\ Departamento de Letras / Universidad de Guadalajara (MÉXICO) \\ CE: gsanchezrobles@yahoo.com
}

DOI: $10.32870 /$ sincronia.axxiii.n76.32b19

(C) $\mathrm{BY} \cdot \mathrm{NC}$

Esta obra está bajo una Licencia Creative Commons Atribución-NoComercial 4.0 Internacional

Recibido: 31/03/2019

Revisado: 07/05/2019

Aprobado: 07/06/2019

\section{RESUMEN}

La celebración del centenario de la muerte del afamado poeta modernista mexicano Amado Nervo es una excelente oportunidad para releer su no tan conocida prosa y descubrir la actualidad que conserva en el siglo XXI. Su novela corta El sexto sentido ofrece una serie de comportamientos enunciativos sobre la presencia del pasado en el futuro, con las oscilaciones y rompimientos de la escritura del tiempo como una de las ideas fundamentales de la comprensión de la realidad. El objetivo es explicar a través de un acercamiento analítico, cómo el pasado se sitúa en el tiempo presente y además organiza y articula el tiempo futuro que el protagonista de este relato -gracias a una insólita intervención quirúrgica- es, literalmente, capaz de prever. Y no sólo eso: al hallar que el pasado como tal se encuentra cargado de registros de un pretérito lejano y repleto de connotaciones míticas, las conclusiones de este análisis ubican a nuestro texto en un nivel genérico más fantástico que propio del terreno de la "ciencia ficción", donde muchos comentaristas lo han colocado. Este 
artículo pretende proponer una lectura sobre la representación y desempeño del tiempo en un relato que entrelaza pasado y futuro, para concluir que la posteridad es el vivo instante del presente.

Palabras clave: Análisis textual. Representación espacial. Manifestación del yo. Determinismo.

\begin{abstract}
:
The one hundredth anniversary of the death of the famed Mexican modernist poet Amado Nervo, is an excellent opportunity to read, once more, his not very wellknown prose and to discover the existent memento in the XXI century. "The sixth sense," one of his stories, offers a series of enunciative behaviors related to the presence of the past in the future, having the oscillations and breaks of the writing of time as one of the essential ideas of understanding reality. Through an analytical approach, we discover the way past time is situated in the present, and likewise organizes and articulates the future that the narrative central character-thanks to an extraordinary surgeryis accurately able to anticipate. And not only that: the past as such is enriched with chronicles of a bygone past filled with mythical inferences, placing our text on a more fantastic generic level than "science fiction" where many critics have placed it. The intention of this article is to propose a reading on the portrayal and performance of time in a narration that entwines past and future concluding that posterity is the living instant of the present time.
\end{abstract}

Keywords: Textual analysis. Spatial representation. Manifestation of the self. Determinism.

Cuando el 24 de mayo de 1919 lo sorprendió la muerte en Montevideo, Amado Nervo, ministro plenipotenciario del gobierno mexicano en Argentina y Uruguay, gozaba de una enorme popularidad como poeta. Había laborado en la docencia, el periodismo y la diplomacia, lo que le permitió vivir además en París y Madrid, así como entablar amistad con otros escritores del prestigio de Rubén Darío y Leopoldo Lugones. Sus restos, que tardaron seis meses en regresar a México, fueron depositados conun gran homenaje en la Rotonda de los Hombres llustres.

El crítico Klaus Meyer Minnerman (2010) explica así la fama del aclamado poeta modernista: 
Desde la publicación de Perlas negras y Místicas, ambos de 1898, hasta el poemario póstumo La amada inmóvil (1920) en el marco de las Obras completas de Amado Nervo al cuidado de Alfonso Reyes, este renombre no había cesado de incrementarse. La poesía de Nervo destacaba por una gran musicalidad verbal, además de la fusión, por discreta no menos sugestiva, de lo sensual con lo religioso, de la expresión morbosa del cansancio "à la fin de la décadence" (Verlaine) con la excitabilidad de los nervios y del sentimiento del tedio de la vida con la nostalgia de la muerte. (p. 277).

Tales características hacían los poemas fácilmente memorizables y durante muchos años, integrados a la educación sentimental de varias generaciones de mexicanos del siglo pasado, fueron declamados en público y en privado. No obstante, poco se sabe que además de doce libros de versos, el escritor nacido en la ciudad de Tepic en 1870 había publicado dieciséis tomos de prosa entre ensayos, cuentos y novelas cortas. La primera de ellas fue El bachiller, que apareció en 1895. Después vendrían Pascual Aguilera, El donador de almas, Otras vidas, Almas que pasan, El diablo desinteresado, El diamante de la inquietud, Una mentira, Amnesia y El sexto sentido (1918), objeto de este trabajo.

El centenario luctuoso de Nervo nos ofrece la oportunidad de honrar su memoria, pero, ¿cómo releerlo en el siglo XXI, más allá de lo postmoderno? Al atractivo de la brevedad en la composición, la narrativa de Juan Crisóstomo Ruiz de Nervo y Ordazaña de una poderosa herramienta estética y cognitiva mediante sus representaciones del tiempo y el espacio, gracias a que como asegura Ramón López Velarde (1971), nuestro autor "respiró, como pocos, en la deliciosa congoja de confundir todas las nociones de cultura, en el esqueleto de lo vital" (p. 504).

La identificación de signos discursivos temporales nos ha llevado a descubrir que los seres humanos existimos históricamente en una multiplicidad de momentos a la vez. Esto nos permite pensar y repensar nuestras circunstancias, cómo vivimos y enunciamos la presencia de otras épocas de la historia y el arte en nuestro presente. Cómo vivimos y enunciamos la presencia del pasado en el presente y en el futuro, cómo nuestra consciencia discursiva oscila entre lo que fue y 
lo que será, pasando por el instante de lo que es. La lectura del relato El sexto sentido (Nervo, 1920, pp. 180-215) nos lleva en busca del tiempo que vendrá. Descubrimos que memoria e invención van de la mano, no importa cuántos eones las separen. Amado Nervo en el pasado, hace más de cien años, intenta aportarnos una hermosa memoria del futuro.

El narrador de El sexto sentido describe en tiempo pasado, pero que es su presente, cómo se sometió con éxito a una operación cerebral experimental, para "ver" el futuro, acción que practicaba a voluntad, con el mismo esfuerzo que hacemos para recordar. De esa forma podía describirse a sí mismo en situaciones futuras y veía pasar sus "yos" "en los mañanas de cada hoy", en "ilusión idéntica a la del viajero del tren, que cree que los árboles y las casas desfilan frente a él" (Nervo, 1920, p. 191). En tales asomos, se obsesiona con la mirada de una niña, a quien llama su Fantasma. Enamorado luego de tal joven, vislumbra la muerte y describe la "previsión" como "el más espantoso privilegio de la vida consciente" (p. 212). Decide entonces cerrar la ventana al futuro y dedicarse al torbellino de la vida mundana, hasta que una tarde, jugando golf, llega hasta él una mujer vestida de blanco. Era ella. Se reconocen y se toman de la mano. Ahí termina el relato e interviene el autor. Comprende que el lector espere conocer "nuestras dichas, nuestros éxtasis, nuestras lágrimas, los horrores y las delicias del privilegio tremendo que me había sido otorgado... ¡Pero para qué, amigos míos, para qué! Esta historia no debe tener fin, creédmelo." (p. 215)

La estructura de esta brevísima novela de Nervo se encuentra organizada en seis capítulos, señalados con numerales romanos del I al VI. Cada uno de ellos puede funcionar como secuencia unitaria de acción, identificable según lo narrado, de la siguiente manera:

I. Disposición a la cirugía.

II. Efectos inmediatos de la operación, sin pormenores técnicos ni científicos. La percepción del futuro se establece como una capacidad de ver la caracterización espacial del porvenir.

III. Interrogatorio del médico al paciente protagonista. Definición de los poderes adquiridos por el personaje, así como el surgimiento del joven fantasma femenino 
que lo obsesiona. La enunciación produce un interés textual por la relación entre el saber y el ignorar, de manera fehaciente.

IV. Saturado por sus capacidades y por la experiencia que le brindan sus poderes, el protagonista opta por acercarse a la vida mundana y real de su momento presente para escapar a sus visiones del futuro. El protagonista reflexiona sobre el futuro y el destino de la humanidad, sobre las utopías que pueden aguardar a los hombres, que podrían convertirse en algo parecido a los dioses.

V. En esta parte-secuencia, el narrador-protagonista vuelve al mundo real, ya como ejemplo vivo del experimento, ya como simple ser humano, que se sigue obsesionando con la visión de una futura mujer amada. En este momento narrativo se refuerza la idea del tiempo futuro como una instancia determinada, como un destino ineludible. Nuestro héroe se topa por fin en el mundo real con su amada.

VI. En la última parte-secuencia del relato, el protagonista se reviste de una conciencia meta textual, puesto que como enunciación afirma que los lectores y testigos de su historia necesitarían de un final para lo que se les ha contado, pero la instancia narrativa misma opta por proporcionarle al lector un final abierto y por tanto no definitivo a lo que ha estado narrando. De este modo, la enunciación le otorga al futuro -combinado con el presente- una calidad permanente, perenne. Hay que hacer notar que a medida que avanza El sexto sentido, la extensión de cada uno de los capítulos se va reduciendo, aunque aumenta la intensidad de lo narrado. La primera parte es mucho más extensa que la final, por ejemplo.

Con base en la metodología sociocrítica de Edmond Cros y en busca de comportamientos textuales productores de sentido, nuestra aproximación a la representación del tiempo pretende obtener de esta obra en prosa de Amado Nervo una serie de marcas que proporcionen fenómenos coherentes de enunciación; es decir, patrones discursivos. Una vez localizados los registros considerados, se establecen unos textos semióticos. Para Cros (2006), "un texto semiótico empieza 
a instituirse en cuanto una de las denotaciones o de las connotaciones de un signo tiene una relación de correferencia con una denotación o una connotación de otro signo" (p. 267). Los textos semióticos nos llevarán a construir unas microsemióticas o sistemas semióticos, que a su vez darán lugar a la "gramática textual" (reglas a partir de las cuales el mismo texto organiza su producción de sentido) expresada en unos ejes de oposición básicos.

Los textos semióticos encontrados pueden denominarse como sigue:

- Ver el futuro

- El futuro como espacio

- Saber vs. Ignorar

- Ciencia para ser dioses / ciencia vs. Religión

- Fantasma

- Destino y determinismo

\section{Ver el futuro}

El primer texto semiótico se establece a partir de la reiteradas menciones de la diégesis. El discurso narrativo representa al tiempo, al futuro mismo, como una imagen visual, como una proyección: "prever", "previsión", "vidente", "lo imprevisto", etc. A continuación se ofrecen sólo unos ejemplos relevantes sobre este fenómeno textual: ${ }^{1}$

“ilmagínese usted el terror, el desconcierto, el desaliento que se apoderarían de nosotros si vislumbrásemos nuestro destino!" (Nervo, 1920, p. 181). ${ }^{2}$

“....esa facultad de percatarse del mañana, de conocerlo, de verlo con la misma visión clara y precisa con que se ve el ayer..." (p. 182).

\footnotetext{
${ }^{1}$ De aquí en adelante, los ejemplos de los textos semióticos mencionados, los presentaré a manera de lista, a fin de que sea comprensible para el lector.

2 Para mayor comprensión del lector, a partir de este momento, las frases correspondientes a las obras de Amado Nervo (1920 y 1991), se presentarán en formato lista.
} 


\begin{abstract}
"seré un vidente mayor que todos los profetas, un oráculo superior a todos los oráculos" (p. 186).
\end{abstract}

"es claro que este vi se refiere a una visión interior, pero material, ya que estaba por imágenes constituida" (p. 189).

"veía yo el futuro como se ven las tiras de papel del kinetoscopio" (p. 190).

“en cuanto a mí, me contemplaba en todos los actos futuros y sucesivos de mi vida” (p. 191).

La enunciación le otorga al futuro no sólo la calidad de imagen, sino también de algo material. La representación del tiempo en El sexto sentido se encuentra regida por la capacidad de apreciación del narrador-protagonista: "de suerte que ya no me era dable tocarlos, poseerlos, identificármelos, pero sí verlos en perspectiva distinta, que iba en sentido opuesto, hasta llegar en brumosos panoramas hasta mi infancia y a mi nacimiento" (p. 192). El tiempo para el héroe de la historia es, sobre todo, un espacio, un lugar que puede ser recorrido tanto hacia adelante como hacia atrás: “...aquella niña que iba a amarme más tarde y yo nos vimos a través del tiempo, con la misma precisión que si nos separase sólo el alféizar de una ventana florida" (p. 195). El tiempo es en sí, una distancia: "cuando nuestras miradas se encontraban a través del tiempo..." (p. 200) El tiempo es, en suma, una impresión física que puede ser apreciada por medio de los sentidos. Cabe mencionar que el relato no lleva a cabo adelantos temporales o prolepsis, es decir, un salto hacia el futuro en el tiempo de la historia, ya que el tiempo dominante siempre será el presente; el narrador heterodiegético es omnisciente y controla toda la información que le proporciona al narratario y al lector. El futuro siempre es enunciado desde el presente y para el presente.

Para la construcción de sus elementos, la enunciación narrativa de este texto reúne una serie de signos específicos. Con el propósito de representar el futuro, lleva a cabo un proceso que conjuga signos pertenecientes a lo material y lo inmaterial, ya que el tiempo es considerado como algo físico, pero también como algo intangible. Muestra una caracterización compleja y hasta 
contradictoria, puesto que es visible e invisible a la vez: el futuro es una visión, una imagen, una posibilidad, pero también es considerado como una obligación, un destino ineludible. El futuro es trazado además como una serie de hechos, de sucesos.

Por otra parte, el futuro es una manifestación del yo, del yo del narrador-protagonista: son sus yoes sucesivos lo que puede apreciar con el talento recién adquirido gracias a la ciencia; el futuro es una revelación y por lo tanto casi una verdad determinista. No obstante, mantiene una curiosa equivalencia con el pasado, ya que el narrador menciona en un momento que le es dado ver claramente el futuro porque puede ver -igual de claro- el pasado: "veo el porvenir, el mío y el de los demás, pero el mío especialmente por la claridad con que contemplo mi pasado" (p. 197). “Absorto ante mi futuro, con la misma devoción con que los viejos se engolfan en su pasado..." (p. 198).

La representación del tiempo, y en específico del futuro, incluye la idea de la utopía. Y esta idea engloba varios signos muy particulares, ya que se relacionarían con la conformación semántica de lo fantástico y lo mítico:

El mundo, llegado a una etapa muy avanzada de desenvolvimiento, ni memoria tenía de que hubiese existido la moneda. Y todo el trabajo, toda la fatiga de los siglos, todo el odiar y el llorar y el anhelar por el oro y para el oro, aparecían entonces inútiles y ridículos, y lo único serio era el pensamiento de los hombres, hecho todo de inmaterial luz y de excelso ensueño. Resueltas las necesidades primordiales de la especie, ésta se angelizaba a diario. (p. 207)

La concepción utópica se relaciona con el avance, la memoria, lo económico, el sufrimiento, el pensamiento, la inmaterialidad, el ensueño, y por último, la cercanía con la transformación en criaturas celestiales.

\section{El futuro como espacio}

El segundo texto semiótico al que quiero referirme es al del futuro como equivalente del espacio. Lo que vendrá es representado como un lugar. Así lo evidencian algunos ejemplos de registros relativos a este aspecto: 
“Cuando el hombre sea más sabio, más sereno, más fuerte, sus sentidos se afinarán de tal manera, que le será dado ver, por fin, lo que está detrás del muro enigmático” (p. 181).

"sólo que nuestra visión actual está limitada a una zona, como está limitado nuestro oído" (pp. 184-185).

"en una lontananza que no estaba construida precisamente por la distancia, sino por la muchedumbre de estados, de actos, de situaciones diversas, mi camino expiraba en vaguedades indecibles, y el panorama, sin aquella como teoría inmóvil de seres y de cosas conmigo relacionadas, continuaba imborrable, lleno de figuras, de formas varias, de acciones por ejecutarse" (p. 191).

"el camino que [ella] parecía seguir era paralelo al mío, luego, iba orientándose hacia mi camino, y, por fin, los dos se confundían en uno que ondulaba entre flores" (p. 193).

"Llegaba hasta la intersección de nuestras vidas y allí deteníame para no anticiparme y empequeñecer así el goce futuro" (p. 199).

Yo podía, único hombre sobre el haz de la tierra, ver mi futuro, pero no acercarlo ni en el espesor de un cabello" (p. 201).

El tiempo futuro contemplado por el protagonista se comporta, según la diégesis, como un ámbito que permite la materialidad, la distancia y el volumen. El tiempo implica entonces, un muro, una zona, un camino, un movimiento espacial.

\section{Saber vs. Ignorar}

El tercer texto semiótico es el del Saber y el Ignorar. El narrador autodiegético del relato de Nervo reitera en su enunciación la importancia de este elemento dual. Propongo que sea doble porque las menciones incluyen simultáneamente las dos posibilidades de significado en una misma 
enunciación. Cuando dice: "y antes de dos siglos, buena parte de la humanidad, los más afinados, lo verán sin duda" (p. 182), la presencia del signo "duda" en la frase denota tanto la ausencia, como la intención de saber. Otras marcas que manifiestan este interés textual por la representación del saber-ignorar:

"Yo no vivo sino para interrogar a la esfinge, rabiosamente... Sólo que la esfinge no me responde..." (p. 183).

“dígamelo, para ir a extenderme a la mesa de su clínica, de donde he de levantarme sabiendo tanto como los dioses" (p.187).

“Pero oh angustia ya presentida por el sabio (p. 193).

"el médico, impaciente y nervioso ante mi silencio, se resolvió por fin a interrogarme de una manera directa" (p. 196).

"El mundo que se me revela es inmenso, indescriptible" (p. 197).

Este texto semiótico implica más de una instancia, ya que los signos connotan la ignorancia de la información, el interés por obtenerla y también la certeza de conseguirla. Aquí hay que añadir el comportamiento de otro registro: el título El sexto sentido. El paratexto señala, como fenómeno textual, una capacidad, el manejo de la información sólo que en un sentido no intelectual, sino relacionado más con la intuición y la experiencia.

Al respecto, en un artículo de 1917, intitulado "La cuarta dimensión", Amado Nervo (1991) aseguraba que los cinco sentidos humanos sólo permiten percibir tres dimensiones. Pero a través de vivencias relacionadas con el espíritu, como el sueño, la hipnosis, la religión y el arte:

[...] ya no hay más que unidad, una pacífica y jubilosa unidad. Lo negro y lo blanco, el mal y el bien, el dolor y la alegría, cesan de existir. Comprendemos que eran sólo limitaciones. El conjunto es indescriptible: de una armonía infinita, para la cual no hay todavía palabra en 
nuestros léxicos. Esta armonía está aún más allá, mucho más allá de la Paz. (Nervo, 1991, p. 911)

Todo lo anterior, además de relacionarse con la cuestión doble del saber y del ignorar, dará paso al aspecto del saber en conexión con la ciencia y lo religioso.

\section{Ciencia para ser dioses / Ciencia vs. Religión}

El cuarto texto semiótico será, por lo tanto: la ciencia para ser dioses, de lo cual se derivará que el concepto de la ciencia se conecta y se opone a la vez, a la religión, al mito. Se ha dicho que este relato de Amado Nervo es de ciencia ficción porque explica en algún momento que la nueva capacidad del personaje proviene de una operación médica. Sin embargo, el protagonista insiste en escamotearle al narratario y al lector la información concreta y precisa sobre la intervención quirúrgica a la que se sometió. Las menciones a la ciencia parecen servir más como un pretexto, un trampolín discursivo, que llevará a los protagonistas y al lector hacia una idea comparativa que une al hombre intervenido con lo divino:

"Mire usted que el sabio que realizase con éxito este experimento, se volvería casi un dios" (Nervo, 1920, p. 185).

“porque toda explicación profanaría la divina realidad de mi ensueño" (p. 197).

"Yo no creo que ningún dios haya gozado lo que yo gozaba amando lo que debía venir (...) Era yo como un Tántalo al revés" (p.200).

"seres que eran la flor y nata de la humanidad porque estaban destinados a cepa de semidioses" (p. 205).

"Y si los desheredados o los tristes de la vida hubiesen podido como yo la grandeza futura de su estirpe, la glorificación de su actual esfuerzo, la divinización de su dolor 
actual, la importancia de este dolor para mejorar el mundo, de seguro que todos hubieran caído en éxtasis." (pp. 205-206).

El narrador insiste en enunciar lo propio de los dioses como una continuación lógica tras haber adquirido su capacidad de "ver" el futuro. En relación con esta idea de lo mítico y lo religioso, elementos a los que la ciencia parece ceder su lugar, encontramos la presencia de lo contemplativo:

Yo sentía derramarme por mi espíritu su mirada, y mis ojos sabían que sus ojos estaban fijos en ellos, y sabían, además, por una sensación como de rechazo fluídico, que los de ella, profundamente azules, recibían a su vez su choque místico...(p. 194)

Como se ha especificado líneas arriba, la generación de sentido en este relato de Amado Nervo no apunta a un texto perteneciente a la ciencia-ficción. H. Pascal (2013) lo sitúa en un ámbito que prefiere llamar "futurista", más dirigido hacia la fantasía, por la presencia reiterada de signos y motivos mítico-religiosos en conexión con el "futuro", el "destino" y la "utopía”. Es tal la presencia de lo mítico, que la figura femenina de la amada es representada como un fantasma.

\section{Fantasma}

Este texto semiótico, el Fantasma, que continúa con nuestro desarrollo descriptivo de los fenómenos de El sexto sentido, afina y problematiza tanto al mito como a la representación del tiempo, puesto que se trata de un "fantasma" del futuro y no del pasado, como las representaciones del sintagma fijo marcan. La instancia narrativa señala que su propia enunciación será explicada a través de la institución discursiva de lo fantástico: “Algo he de dejar a la imaginación de quien me lea, y dejo este periodo de crepúsculo, de alba, mejor dicho, seguro de la fantasía ajena con más colorido que la descripción propia" (Nervo, 1920, p. 188). Este contexto de fantasía se une a los signos que conforman la presencia del "fantasma", puesto que reitera la función de dicha figura. Fantasía equivale a mito, y mito equivale a fantasma, por lo menos en 
términos enunciativos. El protagonista llama "fantasma" a la visión que tiene de una mujer gracias al poder otorgado por la misteriosa operación a la que fue sometido. La mujer no existe, pero existirá en su futuro -cuando la niña crezca-, y el protagonista puede preverla, literalmente. En seguida muestro los registros del relato sobre la presencia del fantasma:

"Había comenzado a vislumbrar estas perspectivas, estos panoramas (...) como un camino poblado de infinitud de fantasmas." (Nervo, 1920, p. 192).

"Mi asiduidad hizo que mirase en relativamente cercano devenir una vida, que suavemente empezaba en no sé qué recodo del futuro a unirse con la mía. Era una mujer, era un rostro... era un fantasma, pero lleno de precisión y de prestigio" (pp. 192-193).

"Mas necesito adaptarme a este nuevo plano, a este nuevo universo... y, sobre todo, quiero estar solo con mi fantasma". "Sí, doctor, con mi fantasma, con mi adorado fantasma. Estoy enamorado de una, ¿cómo llamarle?... de una posibilidad; no, digo mal: estoy enamorado de una imagen, pero de la imagen de una creatura viviente..." (p. 197).

"ansiando con toda el alma encontrarme con mi fantasma" (p. 210).

"supe meterme en un torbellino tal, que ya ni de día ni de noche torné a la dolorosa o plácida contemplación de lo venidero, y ni siquiera fijé una sola vez los ojos interiores en mi fantasma" (p. 213).

La mujer se representa como fantasma por ser, esencialmente, una imagen a la que el protagonista pretende acercarse y alejarse al mismo tiempo. La representación textual de la futura amada del protagonista se conecta con menciones como la fantasía, el poder oracular del narrador-héroe, su precaria auto-semi-divinización, y por lo tanto, el discurso religioso que satura esta obra de Amado Nervo. La cercanía espacial y emocional con la imagen se problematiza porque él sabe que la bella joven será su destino, pero no puede adelantar el tiempo. 


\section{Destino y determinismo}

A propósito del sino, éste será el signo principal que dará lugar a nuestro último texto semiótico: el del destino y el determinismo. Para la enunciación narrativa, el futuro desempeña una función determinista, es decir, se establece como un azar ineludible. Futuro es destino. La relación entre los signos del futuro y del destino genera representaciones ligadas al saber, el afecto, el mito, lo biológico, lo religioso. Prever es predestinar:

“ilmagínese usted el terror, el desconcierto, el desaliento, que se apoderarían de nosotros si vislumbrásemos nuestro destino!" (p. 181).

"aquella mujer que me estaba destinada" (p. 194).

"Ella, en tanto, seguía marchando inconsciente, risueña y juguetona, hacia la inevitable cita que le había dado el destino para arrojarla a mis brazos" (p. 199).

“Complacíame en ansiar el bien que forzosamente debía pertenecerme: en tener sed del agua mística y milagrosa" (p. 200).

"Lo que había de suceder sucedería, con la implacable lentitud de su concatenación rigurosa" (p. 201).

"Se advertían, pues, claros, los designios de la naturaleza...". "Los cristianos hacían bien en considerar el dolor como la predestinación más alta. No sufrían mucho en la vida sino las almas de diamante destinadas a altos fines" (p. 205).

"y amaba ya a la que iba a venir, como si la tuviese por primera vez entre mis brazos" ( $p$. 210). 
El comportamiento textual más consistente, aparte del afectivo, es el que implica lo míticoreligioso. El destino es una fuerza suprahumana que conduce al individuo por encima de todos los demás elementos. La enunciación, ejecutada por el héroe-narrador en la cuarta parte-secuencia del cuento, hace mención de una especie de visión a futuro que se realizará indudablemente, y que al mismo tiempo puede leerse como una crítica social para el presente desde el cual se narran las acciones de la historia:

"Se advertían, pues, claros, los designios inmediatos de la naturaleza: producir mucha gente, una densísima masa humana, para durar a pesar de todo lo aleatorio de la vida, y obtener de esta enorme masa unos cuantos individuos tipo, de los que sólo se logran merced a innumerables coincidencias y circunstancias felices, y que colaboran con el genio de la especie al mejoramiento y a la grandeza de la misma" (p. 204).

“iCuántos infelices vi despreciados por la pomposa suficiencia de nulidades, dando origen a través de sólo tres o cuatro generaciones, a inventores sorprendentes, a reformadores admirables, a pastores de pueblos... mientras que los otros, los orgullosos, solían acabar a través de las mismas generaciones, en un hospital o en un manicomio, en las personas de nietos y bisnietos epilépticos, paralíticos, imbéciles!" (p. 205).

"La humanidad vivía atada a la tierra con una cadena de oro y engañada por el oro mismo presumiendo que sólo dentro de ese torbellino de metal era posible la vida. En un siglo de progreso desigual, en un periodo de mercadería, el hombre iba animalizándose lentamente sin una brizna ya de energías íntimas para las cosas esenciales, para la contemplación del universo" (p. 206).

Esta representación, enunciada como si fuese un pasado contemplado por el narrador heterodiegético, implica de manera connotativa el determinismo biologicista, un aparente mejoramiento de la especie humana, el futuro considerado como la instauración de una justicia racial, el reconocimiento de un progreso falso basado en lo económico. 
El futuro, en este relato de Nervo, no es un porvenir abierto y pleno de posibilidades, sino que se trata de un futuro limitado, un futuro estrecho y determinado: futuro es destino.

\section{Conclusiones}

A modo de conclusiones, propongo que El sexto sentido de Amado Nervo pertenece más a la esfera de lo fantástico que a la de la ciencia ficción, ya que reitera continuamente los factores relativos a lo místico, lo religioso, lo divino, y lo mítico, mientras, al contrario, lo científico-más bien escaso y oscuro- funciona como una directriz que lleva forzosamente a la divinización discursiva de los protagonistas. La fantasía opera como género narrativo en términos cercanos a la fe, a creer lo que se enuncia, mientras que la ciencia ficción se despliega con base en explicaciones minuciosas, en extrapolaciones concretas de lo científico.

Por otra parte, considero que mediante una acción metatextual, puesto que el narradorprotagonista está consciente de que cuenta una historia y de que tiene lectores, El sexto sentido considera al futuro como una instancia permanente. Cito dos ejemplos: "Algo he de dejar a la imaginación de quien me lea, y dejo este periodo de crepúsculo, de alba, mejor dicho, seguro de la fantasía ajena con más colorido que la descripción propia" (Nervo, 1920, p. 188) y el ya aludido final de la obra: "almas ingenuas que no dormís tranquilas hasta que no sabéis el desenlace de una novela, [...] querriáis que yo os dijese lo que pasó después[...] iPero para qué, amigos míos, para qué! Esta historia no debe tener fin, creédmelo..." (p. 215).

Al no tener fin el relato mismo, aquello que narra, el porvenir, tampoco tendrá fin. El futuro es un tiempo continuo. Tal continuidad asegura la constitución de un "después del después"; esta articulación representa un momento que va más allá del futuro mismo, puesto que lo revela como un momento perenne.

Para finalizar, el futuro representado en El sexto sentido consta de elementos tales como el ver, el saber, el destino, lo divino y la permanencia. Los ejes básicos, en términos de microsemióticas, serían los siguientes:

- Revelar - Ocultar (Ver) 
- Saber-Ignorar (Saber)

- Abierto - Cerrado (Destino)

- Divino - Humano (Dioses)

- Permanencia-Cambio (Permanente)

El tiempo futuro construido por los signos interrelacionados de esta novela breve de Amado Nervo se organiza como un tiempo que equivale a un territorio, una circunstancia que se puede mirar, constatable por el sentido de la vista. Es un tiempo cerrado, que no se puede evadir, que ofrece una certidumbre total. Lo que se ve es lo que pasará, ver el futuro es lo mismo que saber el futuro, y es cerrado porque el destino no admite otras posibilidades, no hay opciones para los seres que actúan en este futuro. En esta direccionalidad inevitable, lo humano tiende a preferir una transformación que lo acerque a la divinidad o a las divinidades, y que a través de todos estos fenómenos discursivos, los resultados sean permanentes.

A cien años del fallecimiento de Amado Nervo, nos encontramos re-leyendo y discutiendo su escritura y sus aportaciones. En el "después del después", los lectores del siglo XXI descubrimos en su futuro perpetuo, el vivo instante del presente.

\section{Referencias}

Cros, E. (2009). La Sociocrítica. Madrid: Arco/Libros S.L.

López, R. (1971). "La magia de Nervo", en Martínez, J.L. (editor) Obras. México: Fondo de Cultura Económica.

Meyer-Minnemann, K. (2010). "Entre la truculencia y la sencillez. La narrativa de Amado Nervo", en Olea, R. (editor), Doscientos años de narrativa mexicana: El siglo XIX. México: El Colegio de México.

Nervo, A. (1920). Obras completas de Amado Nervo Vol. XIII. Madrid: Biblioteca Nueva. Nervo, A. (1991). Obras completas Vol. II. México: Aguilar. 
Pascal, H. (2013). La maquinaria lúdica de Amado Nervo. Replicante. Recuperado de https://revistareplicante.com/la-maquinaria-ludica-de-amado-nervo/ 